\title{
An improved ontological representation of dendritic cells as a paradigm for all cell types
}

\author{
Anna Maria Masci ${ }^{1,2,3}$, Cecilia N Arighi ${ }^{4}$, Alexander D Diehl ${ }^{5}$, \\ Anne E Lieberman ${ }^{1}$, Chris Mungall6, Richard H Scheuermann7 ${ }^{7}$, Barry Smith ${ }^{\dagger 8}$ \\ and Lindsay G Cowell*†1
}

\begin{abstract}
Address: ${ }^{1}$ Department of Biostatistics and Bioinformatics, Duke University Medical Center, Durham, NC, USA, ${ }^{2}$ Department of Cellular and Molecular Biology and Pathology, University of Naples, Naples, Italy, ${ }^{3}$ Laboratory of Immunobiology of Cardiovascular Diseases, Department of Medical Science and Rehabilitation, IRCCS San Raffaele Pisana, Roma, Italy, ${ }^{4}$ Protein Information Resource, Georgetown University Medical Center, Washington, DC, USA, ${ }^{5}$ Mouse Genome Informatics, The Jackson Laboratory, Bar Harbor, ME, USA, ${ }^{6}$ Lawrence Berkeley National Laboratory, Berkeley CA, USA, ${ }^{7}$ Department of Pathology, Division of Biomedical Informatics, UT Southwestern Medical Center, Dallas, TX, USA and ${ }^{8}$ Department of Philosophy and Center of Excellence in Bioinformatics and Life Sciences, University at Buffalo, Buffalo, NY, USA

Email: Anna Maria Masci - annamaria.masci@duke.edu; Cecilia N Arighi - cna5@georgetown.edu; Alexander D Diehl - adiehl@informatics.jax.org; Anne E Lieberman - ael7@duke.edu; Chris Mungall - cjm@berkeleybop.org; Richard H Scheuermann - richard.scheuermann@utsouthwestern.edu; Barry Smith - phismith@buffalo.edu;

Lindsay G Cowell* - lgcowell@duke.edu

* Corresponding author †Equal contributors
\end{abstract}

Published: 25 February 2009

BMC Bioinformatics 2009, 10:70 doi:10.1/86/147/-2105-10-70
Received: 19 August 2008

Accepted: 25 February 2009

This article is available from: http://www.biomedcentral.com/I47I-2/05/I0/70

(C) 2009 Masci et al; licensee BioMed Central Ltd.

This is an Open Access article distributed under the terms of the Creative Commons Attribution License (http://creativecommons.org/licenses/by/2.0), which permits unrestricted use, distribution, and reproduction in any medium, provided the original work is properly cited.

\begin{abstract}
Background: Recent increases in the volume and diversity of life science data and information and an increasing emphasis on data sharing and interoperability have resulted in the creation of a large number of biological ontologies, including the Cell Ontology $(\mathrm{CL})$, designed to provide a standardized representation of cell types for data annotation. Ontologies have been shown to have significant benefits for computational analyses of large data sets and for automated reasoning applications, leading to organized attempts to improve the structure and formal rigor of ontologies to better support computation. Currently, the $\mathrm{CL}$ employs multiple is_a relations, defining cell types in terms of histological, functional, and lineage properties, and the majority of definitions are written with sufficient generality to hold across multiple species. This approach limits the CL's utility for computation and for cross-species data integration.
\end{abstract}

Results: To enhance the CL's utility for computational analyses, we developed a method for the ontological representation of cells and applied this method to develop a dendritic cell ontology (DC-CL). DC-CL subtypes are delineated on the basis of surface protein expression, systematically including both species-general and species-specific types and optimizing DC-CL for the analysis of flow cytometry data. We avoid multiple uses of is_a by linking DC-CL terms to terms in other ontologies via additional, formally defined relations such as has_function.

Conclusion: This approach brings benefits in the form of increased accuracy, support for reasoning, and interoperability with other ontology resources. Accordingly, we propose our method as a general strategy for the ontological representation of cells. DC-CL is available from http://www.obofoundry.org. 


\section{Background}

In the last decade, technological developments have resulted in tremendous increases in the volumes and diversity of the data and information that must be processed in the course of biomedical and clinical research and practice, and researchers are under ever greater pressure from funding agencies to share data and to take steps to ensure that data resources are interoperable. The use of ontologies to annotate data has proven successful in supporting these goals and in providing new possibilities for the automated processing of data and information [1-5]. This success has, in turn, resulted in the creation of a large number of ontologies, now made available through the Open Biological Ontologies repository [6] and through the BioPortal of the National Center for Biomedical Ontology [7].

More recently, ontologies have been shown to have significant benefits for the analysis of data resulting from highthroughput technologies [8] and for automated reasoning applications [9-12], which has led to organized attempts to improve the structure and formal rigor of ontologies in ways that will better support computational analysis and reasoning [13].

To help meet the data annotation needs of model organism researchers, Bard and colleagues developed an ontology of cell types [14] that has been widely used for the annotation of data in genome and other biological databases, including biorepository data. To enhance the CL's utility for computational analyses, we developed a systematic approach for the ontological representation of cells as described below, adhering to the principles outlined in [13].

The Cell Ontology (CL) currently contains representations of some 863 cell types, covering cell types from the major model organisms, including prokaryotic, fungal, animal, and plant cell types. This broad scope is accomplished primarily through the use of terms and definitions that can be applied to cell types from multiple types of organisms.

Cell types in CL are classified on the basis of a plurality of structural, histological, functional, and lineage properties. While some terms are provided with natural language definitions, most of the information in CL is conveyed through hierarchical classifications of the cell types along the following multiple axes of classification:

cell by organism

cell by histology

cell by function cell by lineage

cell by nuclear number

cell by ploidy.

Each cell type within the CL is related to at least one supertype via the is_a (subtype) relation, but most CL cell types have multiple supertypes, and are thus classified on multiple axes, a phenonmenon referred to as 'is_a overloading' [15]. CL is currently undergoing review, addressing specifically the problems that arise from the use of multiple modes of classification.

An example of the CL's use of multiple hierarchies is classification of Langerhans cell within the cell by organism and cell by nuclear number hierarchies as a subtype of animal cell and single nucleate cell, respectively (Figure 1). Langerhans cell is further classified within the functional hierarchy (Figure 1) as a subtype of:

\author{
transporting cell \\ professional antigen presenting cell \\ circulating cell \\ motile cell \\ defensive cell \\ phagocyte (sensu Vertebrata).
}

Following a path along both is_a and develops_from relations - the latter is the relation "used to code developmental lineage relationships" - reveals that Langerhans cells are of mesodermal and hematopoietic lineage (Figure 1) [14]. is_a and develops_from are the only relations used in the current version of the CL.

To enhance the CL's utility for computational analyses, we developed a systematic approach for the ontological representation of cells that:

i) separates classification via the is_a relation from the assertion of structural, functional, and lineage properties by using formally defined, property-specific relations, such as has_function

ii) systematically includes both species-neutral and species-specific representations of cell types

iii) defines cell types on the basis of specific combinations of surface proteins used for identification of the cells via flow cytometry. 


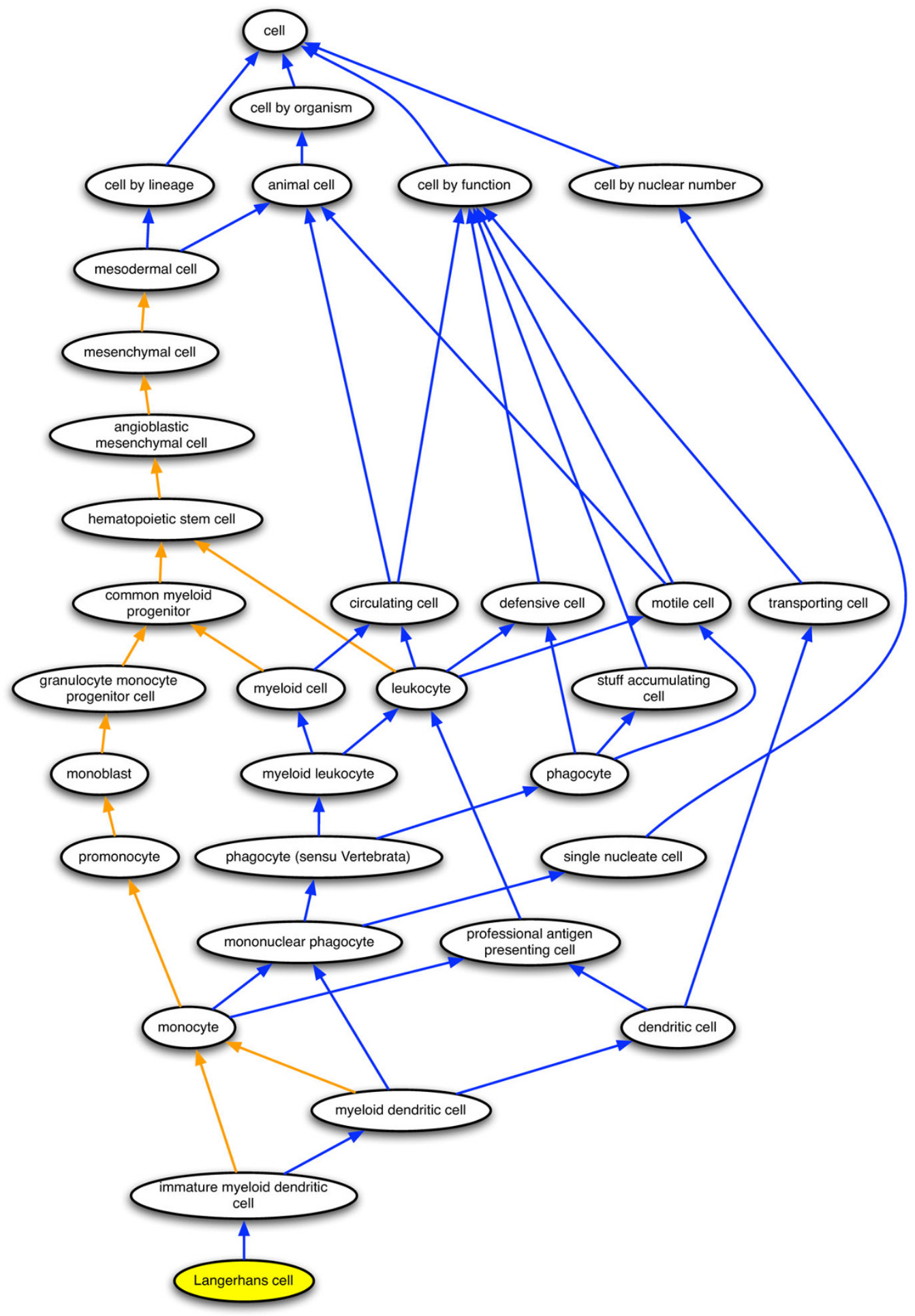

Figure I

The representation of Langerhans cells in the Cell Ontology. A portion of the Cell Ontology is shown with ovals corresponding to cell types defined in the ontology and arrows corresponding to relations between those cell types. Langerhans cell is represented by a yellow oval; blue arrows correspond to is_a relations, and orange arrows correspond to develops_from relations. Only a subset of Langerhans cell parent types are included in the figure. 
We have applied our method to develop an extension of the CL, DC-CL, for dendritic cells (DC), focusing on the DC types observed in mice and humans. The approach we propose increases the amount and accuracy of information contained in DC-CL, enhances its support for crossspecies data integration, and optimizes it for the analysis of flow cytometry data.

The CL currently contains representations of six DC types:

\section{dendritic cell}

plasmacytoid dendritic cell

myeloid dendritic cell

immature myeloid dendritic cell

mature myeloid dendritic cell

\section{Langerhans cell}

which are defined on the basis of structural, functional, and lineage characteristics. The definitions are formulated in a highly general way to ensure broad applicability, but unfortunately at the cost of a precise specification of cell types. For example, plasmacytoid dendritic cell is defined as:

A dendritic cell type of distinct morphology, localization, and surface marker expression from other dendritic cell types and associated with early stage immune responses, particularly the release of physiologically abundant amounts of type 1 interferon in response to infection.

In the immunological literature and research community, the term 'dendritic cell' does not refer to a single, clearly distinguishable cell type; rather it refers to cells from a variety of sub-populations that have different morphologies, are distributed across different microenvironments within the body, express different microbial receptors and surface molecules, and different cytokines [16-18]. Cells in the various subpopulations are referred to using a common term because they are optimized to play a particular role in an immune response, that of priming an immune response by stimulating naïve $\mathrm{T}$ cells in the $\mathrm{T}$ cell zones of secondary lymphoid tissue to proliferate and execute their effector activities, but the cells in the various sub-populations are equipped to detect different pathogens and modulate distinct classes of immune responses. The structural, functional, and lineage similarities and differences between these sub-populations are not yet well understood, however, and their study is challenging because they are sensitive to changes in the cells' microenvironment. The subpopulations are typically characterized using a combination of variables, including flow cytometry or immunohistochemistry markers, function, and anatomical location, but the issue of how to define distinct DC subtypes is still an area of active debate within the immunology community.

We chose DCs as our case study in order to standardize the current terminology and definitions for DC subtypes and provide a common point of reference from which to maintain a common representation of DCs as knowledge about their subtypes evolves. DC-CL employs a flexible framework, which can be amended where necessary as knowledge advances. DC-CL can be used as a reference for the design and description of experiments, the interpretation of experimental results, and the integration of data from different sources, thereby facilitating progress towards a detailed, shared understanding of DC subtypes and/or their roles in immunity and tolerance.

\section{Methods}

To develop a general method for the ontological representation of cell types, we first identified five families of cellular properties that can hold for a given cell type across the various microenvironments in which the cell type can be found. We identified the following five such families of properties:

i) structural components, such as granules in the cytoplasm or molecules on the cell surface,

ii) functions cells of the given type perform,

iii) dispositions, such as the tendency to participate in certain types of processes,

iv) anatomical locations in which the cells are found, and v) lineage relationships.

Among these properties, we emphasize structural components, as these are most often used to identify cell types for study and because their use for classification facilitates maintenance of a single-hierarchy classification of DC types (Figure 2). More precisely, we classify DCs by surface protein expression. For other types of cells, other structural components may be used, as for example in the classification of eosinophils, basophils, and neutrophils, which can be classified on the basis of types of cytoplasmic granules.

We next identified a set of ontology development principles designed to maximize both an ontology's utility for computational analysis and reasoning and its interoperability with existing resources. The basis of this approach is use of relations from the OBO Foundry Relation Ontol- 


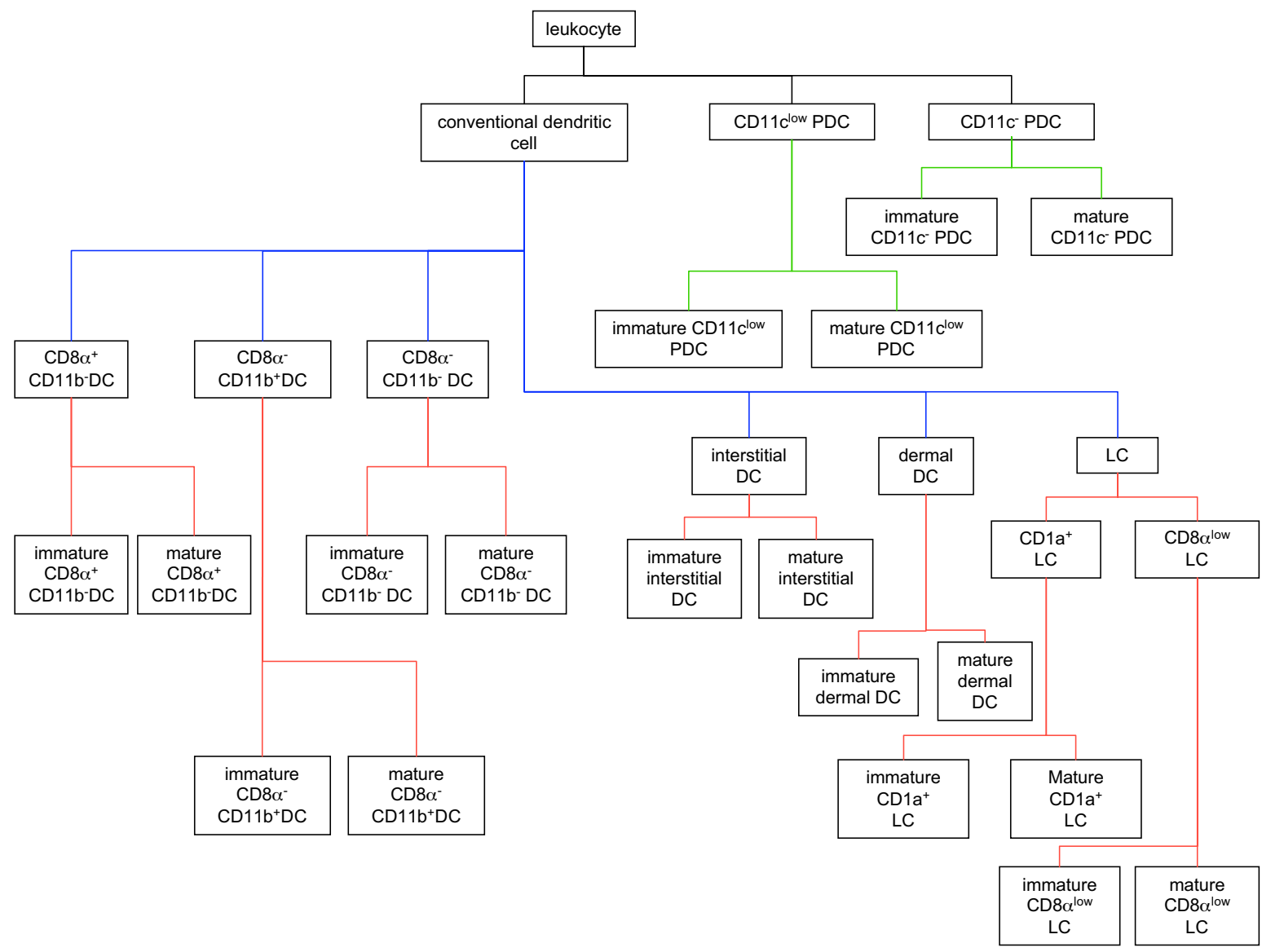

\section{Figure 2}

The representation of dendritic cell types in the Dendritic Cell Ontology (DC-CL). Rectangles correspond to the terms for dendritic cell types represented in DC-CL, and the lines connecting the rectangles correspond to the is_a relations between these cell types. Black lines connect the highest-level terms in DC-CL to the Cell Ontology term leukocyte. Blue lines connect the DC-CL term conventional dendritic cell to the terms for its subtypes, while red lines connect these terms to the respective subtype terms. The green lines connect the terms CD / I c plasmacytoid dendritic cell and CD I I dow plasmacytoid dendritic cell to the terms for their respective subtypes. Abbreviations used in the figure are: DC, dendritic cell; PDC, plasmacytoid dendritic cell; and LC, Langerhans Cell.

ogy (RO) [19] to link terms both within DC-CL and also from DC-CL to other OBO Foundry ontologies (Figure 3), as described in $[13,20]$. Relations in the RO are formally defined to support automated reasoning [19]. In addition, in constructing DC-CL we employed accepted principles of ontology development outlined by the OBO Foundry [13], including the use of genus-differentia definitions [21].

We use RO relations wherever possible, and define new relations where needed, following the approach used in RO. Relations in RO are defined in accordance with the distinction between types and instances [19], corresponding to the standard Description Logic distinction between A-boxes and T-boxes used within the OWL/Semantic Web community [22]. Types are general; they are the kinds of things that exist and are documented in scientific textbooks (e.g. human, red blood cell); instances are particular; they are the specific examples upon which experiments are performed (e.g. J. Craig Venter, the many red blood cells in my body). The relations between types represented in an ontology are defined in terms of relations between the corresponding instances of those types of the sort that can be observed in experiments. Thus, a 


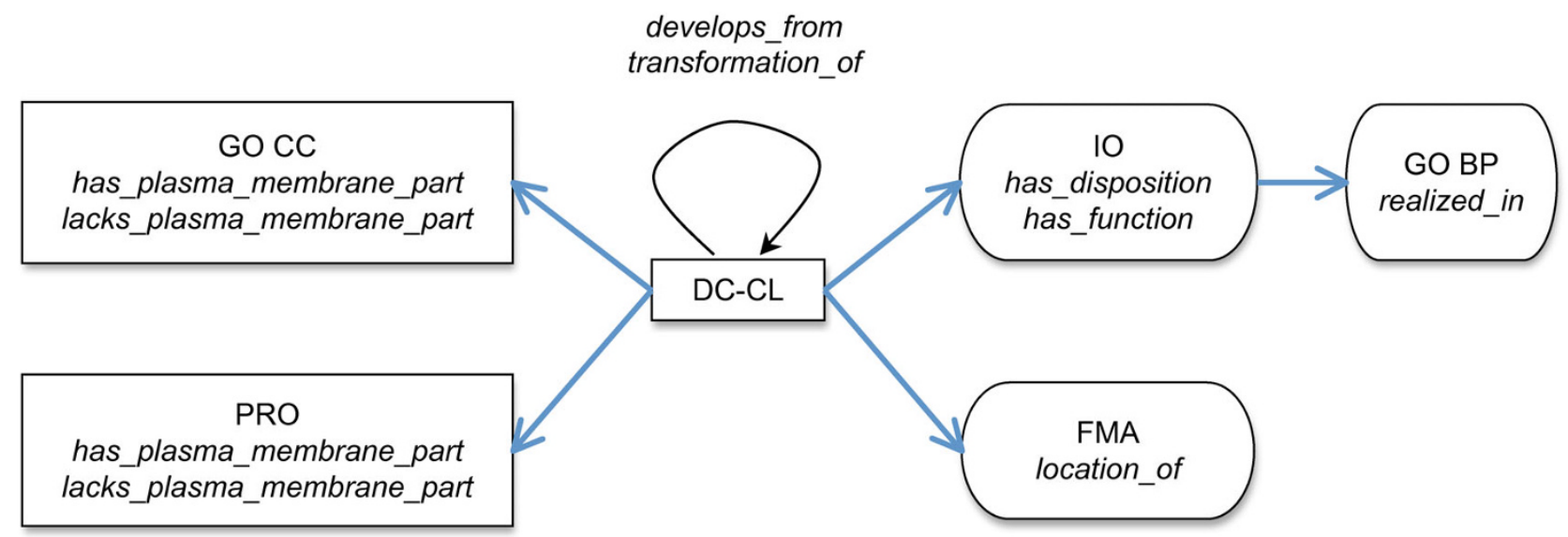

Figure 3

The ontologies and relations referred to in the Dendritic Cell Ontology (DC-CL). The rectangles and ovals represent ontologies, and the arrows represent relations joining terms in the ontologies. Abbreviations for the ontology names are shown in normal font, and the relations used to link DC-CL to each ontology are shown in italics. The black arrow indicates relations used to join DC-CL terms to other DC-CL terms, while the blue arrows indicate trans-ontological relations. Ontologies and relations shown in rectangles are used to define DC-CL types, while the ontologies and relations shown in ovals are used to make non-classificatory assertions about DC-CL types. Abbreviations used in the figure are: GO CC, Gene Ontology Cellular Component Ontology; PRO, Protein Ontology; IO, Immunology Ontology; FMA, Foundational Model of Anatomy; and GO BP, Gene Ontology Biological Process Ontology.

type-level relation $R$ will be defined in terms of the corresponding instance-level relation $\mathbf{R}$ as follows [where italics indicates type-level relations, bold indicates instancelevel relations, type-level variables are denoted by upper case $(\mathrm{X}, \mathrm{Y}, \mathrm{Z}, \ldots)$, and instance-level variables are denoted by lower case italics $(x, y, z, \ldots)]$ :

$\mathrm{X}$ stands_in_R_to $\mathrm{Y}={ }_{\text {def }}$ for every instance $x$ of type $\mathrm{X}$, there exists at least one instance $y$ of type $\mathrm{Y}$, such that $x$ stands_in_R_to $y$.

We use $R(\mathrm{X}, \mathrm{Y})$ and $\mathrm{X} R \mathrm{Y}$ to abbreviate: all Xs stand in $\mathbf{R}$ to some Y. Thus, has_part(human, brain) abbreviates: every instance of human has some instance-level part which is an instance of brain.

Defining type-level relations in terms of all instances of $\mathrm{X}$ ensures that assertions of relations between types hold universally, i.e. XRY will hold only if all instances of $\mathrm{X}$ stand in $\mathbf{R}$ to some instance of $\mathrm{Y}$. This universality in turn ensures the possibility of transitive reasoning by ensuring that relations transitive at the instance level are transitive at the type level. Thus, if $\mathbf{R}$ is transitive and $R$ is defined in terms of $\mathbf{R}$ and all instances of $\mathrm{X}$, then, if $\mathrm{XRY}$ holds at time $\mathrm{t}$ and YRZ holds at $\mathrm{t}, \mathrm{XRZ}$ also holds at $\mathrm{t}$.

\section{Structural Components}

Defining cell types in terms of surface proteins

Cell types in DC-CL are defined in terms of the proteins and protein complexes expressed on the cell surfaces of the corresponding instances, consistent with the characterization of DC populations using surface protein expression [23]. The definitions of such types thus involve terms representing proteins in the Protein Ontology (PRO) [24] and protein complexes in the Gene Ontology Cellular Component Ontology (GO CC) [25]. The reference to proteins and protein complexes enables us to assert the specific presence or absence of defining molecules on cells of a given type. To make these assertions, we define the relations has_plasma_membrane_part and lacks_plasma_membrane_part in terms of the RO instancelevel relations has_part and instance_of and the GO CC term plasma membrane:

We first define the instance-level relation

$c$ has_plasma_membrane_part $p$ at $t={ }_{\text {def }}$ there exists some $m$, such that

$m$ instance_of plasma membrane at $t$

$c$ has_part $m$ at $t$ 
$m$ has_part $p$ at $t$.

We can then define:

Chas_plasma_membrane_part $\mathrm{P}={ }_{\text {def }}$ for all $c$ and all times $t$, if $c$ instance_of $\mathrm{C}$ at

$t$, then there exists some $p$ such that $p$ instance_of $\mathrm{P}$ and $c$

has_plasma_membrane_part $p$ at $t$

C lacks_plasma_membrane_part $\mathrm{P}={ }_{\text {def }}$ for all $c$ and all times $t$, if $c$ instance_of $\mathrm{C}$ at

$t$, then there is no $p$ such that $p$ instance_of $\mathrm{P}$ and $c$

\section{has_plasma_membrane_part $p$ at $t$}

C has_part $\mathrm{P}$ is implied by $\mathrm{C}$ has_plasma_membrane_part $\mathrm{P}$ because both the has_part and has_part relations are transitive. Neither has_plasma_membrane_part nor has_plasma_membrane_part is transitive, however.

Note that there is an important distinction between the two expressions:

\section{C lacks_plasma_membrane_part P}

It is not the case that $\mathrm{C}$ has_plasma_membrane_part $\mathrm{P}$.

The former asserts that there is no instance of the type $\mathrm{C}$ that has an instance of the type $\mathrm{P}$ as a part of its plasma membrane; the latter asserts only that there is at least one instance of the type $\mathrm{C}$ that has no instance of the type $\mathrm{P}$ as part of its plasma membrane.

Using the above-defined relations, definitions for DC-CL types take the form:

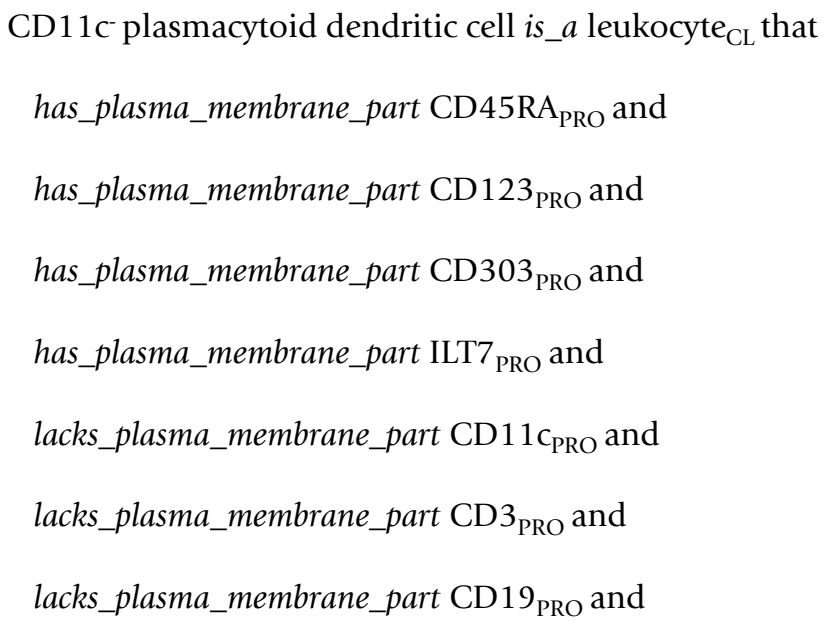

lacks_plasma_membrane_part CD34 $4_{\mathrm{PRO}}$ and

lacks_plasma_membrane_part CD56 $6_{\mathrm{PRO}}$

where the subscripts indicate the ontology source for each term. DC-CL, PRO, and GO CC are thereby linked through the assertion of these trans-ontological relations.

Because no canonical CD11c plasmacytoid DC expresses CD11c on its cell surface, our definition correspondingly includes the assertion: lacks_plasma_membrane_part $\mathrm{CD} 11 \mathrm{c}$. On the other hand, because some CD11c- plasmacytoid DCs will express CCR7 on their surface while others will not, a lacks_plasma_membrane_part CCR7 assertion is not valid for DCs of this type, and neither is a has_plasma_membrane_part CCR7 assertion. The negation of the has_plasma_membrane_part CCR7 assertion is valid in this case, however, and we are exploring the issue of whether assertions of this sort could be useful for the construction of defined classes, collections of cells that do not constitute distinct types yet are identifiable as a group as a consequence of common but not defining characteristics [26]. For example, two defined classes of plasmacytoid DCs might be distinguished, those that do and those that do not express CCR7 on their respective membranes.

\section{Defining cell types by differences in protein expression levels}

For some cell types, including DCs, specification of the level of protein expression is necessary for defining the cell type $[23,27,28]$. Cell types are said to express low or high levels of a protein, the salient amount being relative to the distribution of expression levels among a defined reference population of cells. The relevant reference population of cells is selected on the basis of the cells' possession of certain physical characteristics, such as a particular size and shape or pattern of surface marker expression. In flow cytometry experiments, measurements of forward angle and orthogonal (side) light scatter are used as surrogate measures of cell size and organelle complexity. The relevant population of cells can be defined by forward and side scatter parameters alone, or by using these parameters in conjunction with the expression level of surface proteins additional to the protein of interest.

In the analysis of flow cytometry data, the populations of cells used to generate the reference distribution of expression levels are defined specifically for the context of each experiment. To define cell types ontologically, we select a fixed cell type and refer to the distribution of expression levels among instances of the type in our definition of relations and cell types. For each cell type definition, we select this reference cell type, $C_{R}$, such that the cell type definition referring to $C_{R}$ holds even when instances of the cell type are identified in a particular experiment by protein expression levels relative to a different (i.e. more 
restricted) population of cells. For example, CD11 clow plasmacytoid DCs express low levels of CD11c relative to leukocytes and are defined this way in DC-CL. In flow cytometry experiments, however, such cells are frequently analyzed in reference to a restricted population of leukocytes from which $\mathrm{T}$ cells and NK T cells have been removed.

To include levels of expression in the definition of cell types in DC-CL, we define the two tertiary relations has_high_amount $\left(\mathrm{X}, \mathrm{Y}, C_{R}\right)$ and has_low_amount $\left(\mathrm{X}, \mathrm{Y}, \mathrm{C}_{R}\right)$ that allow us to assert, for example, that entities of type $X$ contain a high amount of $Y$, where 'high' is defined relative to the distribution of expression levels of $\mathrm{Y}$ among entities of type $C_{R}$. These relations will be used to make a series of assertions about the amount of protein $\mathrm{Y}$ expressed by cell type $\mathrm{X}$ relative to the amount of protein Y expressed by a reference cell type $C_{R}$. Such assertions are needed for example to distinguish conventional DCs (CD11c high), CD11c low plasmacytoid DCs, and CD11c negative plasmatcytoid DCs.

To define these relations, we first define the functional operators geometric_mean_of and number_of. The first is defined in the usual way, as a function from a set of numbers to their geometric mean [29]. number_of $(x, \mathrm{Y}, \mathbf{R}, t)$ is defined as the number of instances of type $\mathrm{Y}$ that are related to $x$, an instance of $\mathrm{X}$, by the relation $\mathbf{R}$ at time $t$. Thus for example where $\mathbf{R}$ is the relation has_ part, this results in:

number_of $(x, \mathrm{Y}$, has_ part, $t)=$ def the number of instances $y$ of Y at time $t$ such that $x$ has_part $y$ at $t$

This defines a functional mapping, which yields, for a given cell instance $x$ and time $t$, the number of entities of a given type $Y$ (for example: number of instances of a certain type of molecule) which are part of that cell at that time.

Using these functional operators, we can define has_high_amount as follows:

has_high_amount $(\mathrm{X}, \mathrm{Y}, \mathrm{Z})={ }_{\text {def }}$ for all $x$ and all times $t$, if $x$ instance_of $\mathrm{X}$ at $t$, then there exist some $y, y^{\prime}$ and $z$, such that:

$$
\begin{aligned}
& y \text { instance_of } \mathrm{Y} \text { at } t \\
& y^{\prime} \text { instance_of } \mathrm{Y} \text { at } t \\
& z \text { instance_of } \mathrm{Z} \text { at } t \\
& x \text { has_part } y \text { at } t
\end{aligned}
$$

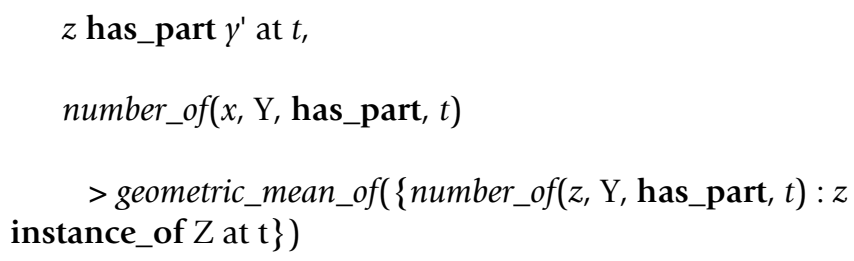

where $\mathrm{Z}$ is a reference cell type, as defined above.

Thus, has_high_amount $(\mathrm{X}, \mathrm{Y}, \mathrm{Z})$ asserts that, for each instance $x$ of $\mathrm{X}$ and for all times at which $x$ is an instance of $\mathrm{X}$, there exist instances $y$ of $\mathrm{Y}$ that are part of $x$, and that the number of such instances $y$ is greater than the geometric mean number of instances that are part of an instance of $\mathrm{Z}$, the reference cell type. has_low_amount $(\mathrm{X}, \mathrm{Y}, \mathrm{Z})$ is similarly defined, substituting the less than $(<)$ relation for the greater than $(>)$ relation. In the context of DC-CL, $\mathrm{X}$ and $\mathrm{Z}$ are cell types, $y$ is a protein or protein complex, and $\mathrm{Y}$ is the corresponding molecule type.

To specify relative amounts of surface expression, we define

$$
\begin{aligned}
& \text { has_high_plasma_membrane_amount }(\mathrm{X}, \mathrm{Y}, \mathrm{Z}) \\
& \text { has_low_plasma_membrane_amount }(\mathrm{X}, \mathrm{Y}, \mathrm{Z})
\end{aligned}
$$

as above, but using has_plasma_membrane_part in place of has_part in the specification of the relevant number_of operators.

In DC-CL, we use leukocyte as common reference cell type, so that the expression levels of a particular molecule on DC subtypes are relative to the distribution of expression levels of that molecule on leukocytes. For convenience, we define

has_high_plasma_membrane_amount_relative_to_leukocyte( $\mathrm{X}, \mathrm{Y})$ as has_high_plasma_membrane_amount $(\mathrm{X}, \mathrm{Y}$, leukocyte), and similarly $\mathrm{X}$ has_low_plasma_membrane_ amount_relative_to_leukocyte $\mathrm{Y}$.

As an example of a DC-CL definition using the

has_high_plasma_membrane_amount_relative_to_leukocyte relation, consider the definition of dermal DCs as having as part CD11b and CD205 (i.e. being CD11b positive and CD205 positive; $\left.\mathrm{CD} 11 \mathrm{~b}^{+} \mathrm{CD} 205^{+}\right)$, having high amounts of CD11c (CD11 $\left.\mathrm{c}^{\text {high }}\right)$, and lacking CD8 $\alpha$ (CD8 $\left.\alpha^{-}\right)$:

dermal dendritic cell ${ }_{\mathrm{DC}-\mathrm{CL}}$ is_a leukocyte $\mathrm{CL}_{\mathrm{CL}}$ that has_plasma_membrane_part CD11 $\mathrm{b}_{\mathrm{PRO}}$ and has_plasma_membrane_part CD205 $5_{\text {PRO }}$ and 
has_high_plasma_membrane_amount_relative_to_leukocy te $\mathrm{CD} 11 \mathrm{c}_{P R O}$ and

lacks_plasma_membrane_part $\mathrm{CD} 8 \alpha$ homodimer $\mathrm{GO}_{\mathrm{GC}}$

To assess whether the geometric mean represents an appropriate threshold to distinguish high and low expressing cells, we analyzed histograms of fluorescence intensities for CD11c, CD11b, CD45R, CD80, CD86, and MHC II under the assumption that the number of molecules of the relevant type on the cell surface is correlated with the fluorescence intensity after staining for the molecule of interest. Spleens were removed from untreated mice, erythrocytes were lysed, and the cells were incubated with the appropriate fluorescence-labeled antibody or isotype control, as described in [30]. Histograms for each molecule type were generated after gating on appropriate forward and side scatter values to exclude dead cells and gating on fluorescence intensity to exclude cells that do not express the molecule of interest. For each histogram, the geometric mean of fluorescence intensities was computed and evaluated as a threshold for classifying high versus low expressing cells (data not shown). We found that the geometric mean computed on the fluorescence intensities of positive cells provides good discrimination between high and low expressing cells. While a formal analysis of the utility of the geometric mean of fluorescence intensities for the classification of cells remains to be carried out and is beyond the scope of this paper, this initial analysis provides support for the use of the geometric mean in the definition of the relations has_high_amount and has_low_amount.

\section{Species specificity of DC-CL cell types}

To best facilitate cross-species data interoperability, ontologies need to provide both species-neutral and speciesspecific terms. Species-neutral terms allow for commonalities between species to be identified. Such commonalities can be used for the generation of hypotheses not only about human biology from experimental results observed in model organisms but also about basic principles, such as those underlying cell biology or mammalian biology. Species-specific terms are equally important, however, as they allow for the more accurate and precise representation of information and data pertaining to organisms of different species and thus enable us to capture more precisely the differences between such organisms.

The approach we outline for defining cell types in DC-CL results in the systematic inclusion of both species-neutral and species-specific terms and allows prospectively for the systematic capture of orthology relationships between species-specific types, where they exist. Because we define cell types by linking to species-neutral terms in PRO and GO CC, cells expressing the same combination of surface proteins are instances of the same DC-CL type, regardless of their species of origin. For example, cells that are CD11 $\mathrm{c}^{+}$and CD19- CD3- C34- CD56- are referred to as conventional dendritic cells in both mice and humans, and instances of such cells in mice and in humans are instances of the DC-CL type conventional dendritic cell. Species-specific terms arise not because we use species of origin as a defining characteristic, but rather because the DC types identified in mice and humans express different combinations of surface proteins. For example, the cells referred to as plasmacytoid dendritic cells in mice are marked by expression of CD45R, GR1, and CD11c and the absence of CD11b, while in humans, plasmacytoid dendritic cells are marked by expression of CD45RA, CD123, CD303, and ILT7. Thus, in DC-CL, we have CD11 $\mathrm{c}^{+}$and CD11 $\mathrm{c}^{-}$plasmacytoid dendritic cells, corresponding to those observed in mice and humans, respectively.

PRO includes multiple levels of classification for proteins, including a gene product level, a sequence variant level (e.g. for genetic differences), a protein isoform level (e.g. for splice variants), and a post-translational modification level $[24,31]$. PRO is species-neutral in the sense that, proteins from different species that are the products of orthologous genes are instances of the same PRO gene product level type, and proteins from different species representing equivalent forms (e.g. CD45RA in human and mouse) are instances of the same sequence variant level or protein isoform level types. Likewise, protein forms from different species with equivalent post-translational modifications are instances of the same post-translational modification level type. The protein complex types represented in GO $\mathrm{CC}$ are similarly species-neutral. Although the curation of PRO has thus far focused on inclusion of types corresponding to the protein instances observed in mice and humans, future PRO curation efforts will ensure broader species inclusivity.

To avoid the unnecessary creation of overly specific subtypes, we define cell types in terms of PRO gene product level types, and recommend that PRO types at this level be used wherever possible. When necessary, however, representations of more specific protein types can be used. For example, the alternative splice forms CD45RA and CD45RO may be needed to define some T lymphocyte subtypes by linking to the corresponding PRO protein isoform level types [32].

When species-specific cell types are defined either through the use of species-specific combinations of PRO gene product level types or through the use of PRO types corresponding to species-specific amino acid sequences, the relationships between protein types in PRO provide the information needed to identify cell types expressing related proteins. 


\section{Functions and Dispositions}

The backbone is_a hierarchy that is used in formulating definitions of DC-CL terms is based on the types and levels of proteins expressed on the cell surface. DC-CL also includes, however, further relations that are used in assertions about the functions each of the cell types performs and about their dispositions to participate in processes of specific types. Assertions about functions are made by linking terms in DC-CL to terms referring to types of functions using the RO relation has_function. Similarly, assertions about dispositions are made using the RO relation has_disposition.

The terms for cellular functions and dispositions are linked to GO biological process (GO BP) terms using the RO relation realized_in, in axioms of the form:

$$
\begin{aligned}
& \mathrm{X} \text { realized_in } \mathrm{Y}_{\mathrm{GO} \mathrm{BP}} \\
& \mathrm{X} \text { realized_in } \mathrm{Y}_{\mathrm{GO} \mathrm{BP}} \text {. }
\end{aligned}
$$

where $\mathrm{Y}$ is a process type from GO BP. For example:

antigen processing activity ${ }_{\text {DC-CL }}$ realized_in antigen processing and presentation $\mathrm{GO}_{\mathrm{BP}}$

disposition to cross-present antigen to $\mathrm{CD}^{+} \mathrm{T}^{\mathrm{T}}$ cells $\mathrm{DC}_{\mathrm{DCL}}$ realized_in antigen presentation, exogenous antigen via MHC class $\mathrm{I}_{G O B P}$.

Where the representation of functions and dispositions needed for DC-CL requires reference to a process for which we could find no corresponding GO BP term, we have submitted a term request to the Gene Ontology tracker [33].

\section{Locations}

Assertions about the anatomical location of DC subtypes are made by relating DC subtype terms to terms in the Foundational Model of Anatomy [21], using assertions of the form:

$$
\mathrm{Y}_{\mathrm{FMA}} \text { location_of } \mathrm{X}_{\mathrm{DC}-\mathrm{CL}}
$$

which states that every instance of the anatomical structure type $\mathrm{Y}$ is the location of some instance of the DC type $\mathrm{X}$. For example:

lymph node $e_{\mathrm{FMA}}$ location_of mature CD $8 \alpha^{-}$CD11c- dendritic cell ${ }_{\mathrm{DC}-\mathrm{CL}}$

While this is an ontological assertion about an anatomical entity rather than about a cell type, inclusion of assertions of this form allows the ontology to be queried for the anatomical locations in which the various DC types can be found. They also serve to link DC-CL to other ontologies within the OBO Foundry, and thus serve more general networking of information in a way that provides support for further types of reasoning.

\section{Lineage Relationships between Cell Types}

Lineage relationships between cell types are captured using the arises_from and the transformation_of relations. The relations arises_from, derives_from and transformation_of are formally defined in the RO [19]. derives_from, the instance-level relation, is defined as the relation between "distinct material continuants when one succeeds the other across a temporal divide in such a way that at least a biologically significant portion of the matter of the earlier continuant is inherited by the latter" [19]. There are three types of derives_from relations, the continuation of an instance that loses a small portion of itself, fusion, such as the fusion of a sperm and an egg to form a zygote, and fission, such as the division of a cell to form two daughter cells. derives_from, the class-level relation, is the relation between classes $C$ and $C^{\prime}$ when instances of $C$ are connected to instances of $\mathrm{C}^{\prime}$ by a series of derives_from relations [19].transformation_of is defined as the relation between two classes, in which "one and the same continuant entity preserves its identity while instantiating distinct classes at distinct times" [19]. That is, a single instance is of type $\mathrm{C}$ at one time and of type $\mathrm{C}^{\prime}$ at a later time, as in the transformation from child to adult. arises_from is the parent relation of derives_from and transformation_of.

In DC-CL, we use transformation_of as the relation between immature and mature cell types because we are asserting a one-to-one relationship between instances of the types. All other lineage relationships, such as that between hematopoietic stem cells and common lymphoid precursors, are asserted using the arises_from relation because the relationship between instances may not be one-to-one.

\section{Results \\ DC-CL cell types}

Terms for 29 DC types are defined in DC-CL, along with 12 precursor cell types, which are defined in order to assert lineage relationships. All DC types are subtypes of conventional dendritic cell, CD11 $c^{\text {low }}$ plasmacytoid dendritic cell, or CD11c-plasmacytoid dendritic cell (Table 1).

The type conventional dendritic cell has 22 subtypes identified in the current version of DC-CL; CD11 clow plasmacytoid dendritic cell and CD11c- plasmacytoid dendritic cell each have 2 subtypes. The surface protein combinations that define these subtypes are shown in Tables 2 and 3, respectively; the placement of these types in the DC-CL hierarchy is shown in Figure 2. 
Table I: The genus-differentia form of the definitions for the three most general types in DC-CL.

\begin{tabular}{|c|c|c|c|}
\hline DC-CL Term & Genus & Differentia & \\
\hline \multirow[t]{5}{*}{ conventional dendritic cell } & leukocyte $_{\mathrm{CL}}$ & has_high_plasma_membrane_amount & CDII $C_{P R O}$ \\
\hline & & lacks_plasma_membrane_part & $\mathrm{CD} 3_{\mathrm{PRO}}$ \\
\hline & & lacks_plasma_membrane_part & CDI9 $9_{\mathrm{PRO}}$ \\
\hline & & lacks_plasma_membrane_part & CD34 $4_{\text {PRO }}$ \\
\hline & & lacks_plasma_membrane_part & CD56 \\
\hline \multicolumn{4}{|l|}{ CDII low } \\
\hline \multirow[t]{8}{*}{ plasmacytoid dendritic cell } & leukocyte $_{\mathrm{CL}}$ & has_low_plasma_membrane_amount & $C D \mid I C_{P R O}$ \\
\hline & & has_plasma_membrane_part & CD45R $R_{\text {PRO }}$ \\
\hline & & has_plasma_membrane_part & $G R I_{P R O}$ \\
\hline & & lacks_plasma_membrane_part & $C D I I b_{P R O}$ \\
\hline & & lacks_plasma_membrane_part & $\mathrm{CD} 3_{\mathrm{PRO}}$ \\
\hline & & lacks_plasma_membrane_part & CDI9 $9_{\text {PRO }}$ \\
\hline & & lacks_plasma_membrane_part & CD34 \\
\hline & & lacks_plasma_membrane_part & CD56 $6_{\text {PRO }}$ \\
\hline \multicolumn{4}{|l|}{ CDIIc- } \\
\hline \multirow[t]{9}{*}{ plasmacytoid dendritic cell } & leukocyte $_{\mathrm{CL}}$ & has_plasma_membrane_part & $C D 45 R A_{P R O}$ \\
\hline & & has_plasma_membrane_part & CDI23 $\mathrm{PRO}$ \\
\hline & & has_plasma_membrane_part & CD $303_{\text {PRO }}$ \\
\hline & & has_plasma_membrane_part & ILT7 \\
\hline & & lacks_plasma_membrane_part & $C D I I C_{P R O}$ \\
\hline & & lacks_plasma_membrane_part & $\mathrm{CD} 3_{\mathrm{PRO}}$ \\
\hline & & lacks_plasma_membrane_part & CDI9 $9_{\text {PRO }}$ \\
\hline & & lacks_plasma_membrane_part & CD34 $4_{\text {PRO }}$ \\
\hline & & lacks_plasma_membrane_part & CD56 \\
\hline
\end{tabular}

The precursor cell types are not DC subtypes, and are therefore not placed in the DC-CL hierarchy. We define them for completeness, however, in order to provide surface protein-based definitions for all cell types referred to in DC-CL assertions. The surface protein combinations that define the 12 precursor types are shown in Tables 4 and 5 .

In addition to defining the DC types by the presence or absence of specific surface proteins, we include assertions about which of the Toll-like receptors (TLR) are expressed on each DC type. Future work on DC-CL will include incorporation of assertions about other molecules important to immune function, such as additional pattern recognition receptors and cytokine receptors.

\section{Functions and Dispositions}

The DC types in DC-CL are related to functions (Table 6) and dispositions (Table 7) using the has_function and has_disposition relations. The six plasmacytoid dendritic cell types all share a common disposition to secrete type 1 interferon. Additional functions and dispositions for the subtypes of conventional dendritic cell and for the plasmacytoid dendritic cell subtypes are shown in Tables 8, 9 and 10.

Assertions in DC-CL are associated with reference to at least one journal article via PubMed ID.

\section{Discussion}

We present here an ontology of DC types (DC-CL) and the method used to create the ontology. The motivation for developing DC-CL was two-fold: to provide a common point of reference for standardized terms and definitions for DC subtypes and to develop a method for representing cell types that is highly computable and builds on existing resources. DCs have a particularly complicated biology [16-18]; thus not only are efforts to develop standardized, comprehensive information resources needed, but DCs are a good model for testing a method for representing cells in an ontology.

We have developed DC-CL using a systematic approach for the ontological representation of cells that:

i) separates classification via the is_a relation from the assertion of structural, functional, and lineage properties by using formally defined, property-specific relations, such as has_function

ii) systematically includes both species-neutral and species-specific types

iii) defines cell types on the basis of specific combinations of surface proteins used for identification of the cells via flow cytometry. 
Table 2: Surface protein combinations defining the subtypes of conventional dendritic cell.

\begin{tabular}{|c|c|c|c|c|c|c|c|c|c|c|c|c|c|c|c|}
\hline & 205 & $\mathrm{IIb}$ & 4 & $8 \alpha$ & la & 206 & 209 & 36 & 14 & 207 & 324 & 80 & 83 & 86 & $\begin{array}{c}\mathrm{MHC} \\
\text { II }\end{array}$ \\
\hline$C D 8 \alpha-C D \mid I b-D C$ & + & - & - & - & & & & & & & & & & & \\
\hline immature & + & - & - & - & & & & & & & & $\mathrm{L}$ & & $\mathrm{L}$ & $\mathrm{L}$ \\
\hline \multicolumn{16}{|l|}{$C D 8 \alpha-C D \mid l b-D C$} \\
\hline mature & + & - & - & - & & & & & & & & $\mathrm{H}$ & + & $\mathrm{H}$ & $\mathrm{H}$ \\
\hline \multicolumn{16}{|l|}{$C D 8 \alpha-C D \mid l b-D C$} \\
\hline$C D 8 \alpha-C D I I b+D C$ & - & + & + & - & & & & & & & & & & & \\
\hline immature & - & + & + & - & & & & & & & & $\mathrm{L}$ & & $\mathrm{L}$ & $\mathrm{L}$ \\
\hline \multicolumn{16}{|l|}{$C D 8 \alpha-C D I I b+D C$} \\
\hline mature & - & + & + & - & & & & & & & & $\mathrm{H}$ & + & $\mathrm{H}$ & $\mathrm{H}$ \\
\hline \multicolumn{16}{|l|}{$C D 8 \alpha-C D I I b+D C$} \\
\hline$C D 8 \alpha+C D \mid I b-D C$ & + & - & - & + & & & & & & & & & & & \\
\hline immature & + & - & - & + & & & & & & & & $\mathrm{L}$ & & $\mathrm{L}$ & $\mathrm{L}$ \\
\hline \multicolumn{16}{|l|}{ CD8 $\alpha+C D \mid l b-D C$} \\
\hline mature & + & - & - & + & & & & & & & & $\mathrm{H}$ & + & $\mathrm{H}$ & $\mathrm{H}$ \\
\hline \multicolumn{16}{|l|}{$C D 8 \alpha+C D \mid l b-D C$} \\
\hline interstitial DC & & + & & & + & + & + & & & & & & & & \\
\hline immature & & + & & & + & + & + & & & & & $\mathrm{L}$ & & $\mathrm{L}$ & $\mathrm{L}$ \\
\hline \multicolumn{16}{|l|}{ interstitial DC } \\
\hline mature & & + & & & + & + & + & & & & & $\mathrm{H}$ & + & $\mathrm{H}$ & $\mathrm{H}$ \\
\hline \multicolumn{16}{|l|}{ interstitial DC } \\
\hline \multicolumn{16}{|l|}{ Langerhans cell } \\
\hline CDIa+ Langerhans cell & & & & & + & & & & & + & + & & & & \\
\hline immature CDla+ & & & & & + & & & & & + & + & $\mathrm{L}$ & & $\mathrm{L}$ & $\mathrm{L}$ \\
\hline \multicolumn{16}{|l|}{ Langerhans cell } \\
\hline mature $\mathrm{CDla}+$ & & & & & + & & & & & + & + & $\mathrm{H}$ & + & $\mathrm{H}$ & $\mathrm{H}$ \\
\hline \multicolumn{16}{|l|}{ Langerhans cell } \\
\hline CD8 $\alpha^{\text {low }}$ Langerhans cell & $\mathrm{H}$ & & & $\mathrm{L}$ & & & & & & + & & & & & \\
\hline immature $\mathrm{CD} 8 \alpha^{\text {low }}$ & $\mathrm{H}$ & & & $\mathrm{L}$ & & & & & & + & & $\mathrm{L}$ & & $\mathrm{L}$ & $\mathrm{L}$ \\
\hline \multicolumn{16}{|l|}{ Langerhans cell } \\
\hline mature CD8 $\alpha^{\text {low }}$ & $\mathrm{H}$ & & & L & & & & & & + & & $\mathrm{H}$ & + & $\mathrm{H}$ & $\mathrm{H}$ \\
\hline \multicolumn{16}{|l|}{ Langerhans cell } \\
\hline dermal DC & + & + & & - & & & & & & & & & & & \\
\hline immature dermal DC & + & + & & - & & & & & & & & $\mathrm{L}$ & & $\mathrm{L}$ & $\mathrm{L}$ \\
\hline mature dermal DC & + & + & & - & & & & & & & & $\mathrm{H}$ & + & $\mathrm{H}$ & $\mathrm{H}$ \\
\hline
\end{tabular}

Column headings show protein or protein complex names. Numbers correspond to CD antigens (e.g. CD205 is referred to as 205 in the table). Row labels show the terms for subtypes of conventional dendritic cell defined in DC-CL. Row labels not indented correspond to direct subtypes of conventional dendritic cell; indented row labels correspond to direct subtypes of the types referred to by the nearest, above row with less indent. + indicates that the has_plasma_membrane_part relation is use to join the cell type term to the protein or protein complex term; - indicates that the lacks_plasma_membrane_part relation is used; $\mathrm{L}$ indicates that the has_low_plasma_membrane_amount relation is used; and $\mathrm{H}$ indicates that the has_high_plasma_membrane_amount relation is used.

The use of property-specific relations, such as has_function, to incorporate structural, functional, and lineage properties has many benefits. First, this approach eliminates many of the errors that frequently result from multiple uses of the is_a relation [34-36] in what has been called 'is_a overloading' [15]. Second, the is_a relation can only be used between entities of the same ontological category (higher level types, such as those found in the Basic Formal Ontology described below), while specific relations can be used to relate cells to entities in other categories, such as functions (has_function), molecules (has_part), and processes (participates_in), that are represented within their own ontologies. DC-CL is formally connected to the hierarchical structure and relations of these ontologies, as well as the data annotated in their terms, thereby providing significant additional information and opportunities for data integration. The use of property-specific relations also allows us, without sacrificing expressive power, to 
Table 3: Surface protein combinations defining the subtypes of CDI lc- plasmacytoid dendritic cell and CDI I clow plasmacytoid dendritic cell.

\begin{tabular}{|c|c|c|c|c|c|c|c|c|c|c|c|c|}
\hline & 123 & 303 & ILT7 & $45 \mathrm{RA}$ & $45 R$ & GRI & IIc & $\mathrm{Ilb}$ & 80 & 83 & 86 & $\underset{\text { II }}{\text { MHC }}$ \\
\hline immature CDI Ic- plasmacytoid DC & + & + & + & + & & & - & & - & & $\mathrm{L}$ & $\mathrm{L}$ \\
\hline mature CDII c- plasmacytoid DC & + & + & + & + & & & - & & $\mathrm{H}$ & + & $\mathrm{H}$ & $\mathrm{H}$ \\
\hline immature CDI I clow plasmacytoid DC & & & & & + & + & L & - & $\mathrm{L}$ & & $\mathrm{L}$ & \\
\hline mature CDI I clow plasmacytoid DC & & & & & + & + & L & - & $\mathrm{H}$ & + & $\mathrm{H}$ & $\mathrm{H}$ \\
\hline
\end{tabular}

Other details are as in Table 2.

maintain a policy of single inheritance (each representational unit in the ontology has maximally one single asserted is_a parent), which brings benefits such as clearer statement of definitions, easier and more reliable curation, ability to use more powerful reasoning tools, and the ability to have a unique measure of distance between any two terms on the same branch of an ontology. Finally, the use of property-specific relations enhances ontologies for computational analyses because each relation can be defined with its own inference properties.

The inclusion of species-specific cell types allows for the more specific annotation of data and for the incorporation within DC-CL of species-specific properties, many of which have important functional consequences. For example, the plasmacytoid DCs observed in humans (CD11c) express Toll-like receptors (TLR) TLR7 and TLR9, while the plasmacytoid DCs observed in mice (CD11 low) express all mouse TLRs except for TLR3 and TLR4, with consequent differences in the types of pathogens human and mouse plasmacytoid DCs can detect [37]. We avoid use of species of origin as a basis of defining types, however, and only define types based on the presence or absence of specific surface proteins. Thus, the plasmacytoid DCs observed in humans are instances of the type CD11c-plasmacytoid dendritic cell, while the plasmacytoid DCs observed in mice are instances of the type CD11 clow plasmacytoid dendritic cell, where the two types are defined by the patterns of surface protein expression given in the above definitions. Plasmacytoid DCs observed in a third species to have either pattern of surface protein expression would be instances of the corresponding type.
In addition, we only include assertions about the cell types that hold across all species in which the type is observed. In this way, the inclusion of species-specific DC types in DC-CL facilitates understanding of the similarities and differences between mouse and human immunology and improved capacity for generating hypotheses about the human immune response from the interpretation of the results of mouse experiments. In this way DCCL also fosters the advance of translational medicine.

To define cell types on the basis of species of origin, or to include assertions that hold for the type in one species but not another, we recommend the creation of species-specific extensions rather than the inclusion of such types in CL or DC-CL. This approach allows for the representation of detailed, species-specific information without using multiple modes of classification (structure and species of origin) or including conflicting assertions in the core ontology. The approach of more specific extensions of a core template ontology has been used successfully in the creation of species-specific anatomy ontologies as extensions of the Common Anatomy Reference Ontology (CARO) [38] and in the creation of ontologies of specific infectious diseases as extensions of the core Infectious Disease Ontology (IDO) [39].

The use of specific combinations of surface proteins to define DC subtypes has advantages both for the creation of DC-CL and for its application to the analysis of cellular data. A primary means by which experimentalists distinguish cell types is by distinguishing patterns of protein expression using flow cytometry. Defining DC subtypes in

Table 4: Surface protein combinations used to define DC precursors in DC-CL.

\begin{tabular}{|c|c|c|c|c|c|c|c|c|c|c|c|c|c|c|c|c|c|}
\hline & 7 & $45 R A$ & 4 & 3,19 & 34 & 123 & 10 & 71 & 133 & 33 & $2,1 \mathrm{Ib}, 15,56$ & 16 & IIC & 31 & 32 & 43 & 86 \\
\hline CD7-lymphoid precursor & - & - & - & - & + & & & & & & & & & & & & \\
\hline $\mathrm{CD7}^{+}$lymphoid precursor & + & - & - & - & + & & & & & & & & & & & & \\
\hline granulocyte-monocyte precursor & & + & - & - & + & + & & & & & & & & & & & \\
\hline $\mathrm{CDIO}^{+}$common lymphoid precursor & + & + & - & - & + & & + & & & & & & & & & & \\
\hline CD7I+ common myeloid precursor & - & + & - & - & + & & - & + & & & & & & & & & \\
\hline CDI33+ hematopoietic stem cell & & & & - & + & & & - & + & - & - & - & & & & & \\
\hline $\mathrm{CD} 43^{+}$monocyte & & & & & & & & & & + & & & + & + & + & + & + \\
\hline
\end{tabular}

Other details as in Table 2. 
Table 5: Surface protein combinations used to define DC precursors in DC-CL.

\begin{tabular}{|c|c|c|c|c|c|c|c|c|c|c|c|c|}
\hline & 117 & 16 & 135 & M- CSFR & 217 & SCAI & $\begin{array}{c}2,3,4,5,8,45 R, \text { GRI, NKI.I, Ter- } \\
\text { II9 }\end{array}$ & 32 & 34 & 90 & 115 & $\mathrm{Ilb}$ \\
\hline common dendritic precursor & + & & + & + & & & & & & & & \\
\hline $\begin{array}{l}\text { CD217+ common lymphoid } \\
\text { precursor }\end{array}$ & + & & & & + & + & - & & & & & \\
\hline CDII7+ common myeloid precursor & + & + & & & - & - & - & + & + & & & \\
\hline SCAI+ hematopoietic stem cell & + & & & & & + & - & & - & - & & \\
\hline CDII5+monocyte & & & & & & & & & & & + & + \\
\hline
\end{tabular}

Other details as in Table 2.

Table 6: DC-CL function terms and their corresponding GO BP process terms.

\begin{tabular}{|c|c|}
\hline DC-CL Function Term & GO BP Process Term \\
\hline \multicolumn{2}{|l|}{ antigen capture activity } \\
\hline antigen processing activity & dendritic cell antigen processing and presentation \\
\hline antigen presentation activity & dendritic cell antigen processing and presentation \\
\hline \multicolumn{2}{|l|}{ antigen transportation activity } \\
\hline cytokine secretion activity & cytokine secretion \\
\hline
\end{tabular}

terms of flow markers allows easy incorporation into DC$\mathrm{CL}$ of new discoveries about DCs deriving from experiments involving flow cytometry to isolate or analyze cell populations. Similarly, defining DC subtypes in terms of flow markers optimizes DC-CL for the annotation, analysis, and integration of flow cytometry data and of data deriving from experiments in which fluorescence-activated cell sorting is used as a source of cells. Just as the Gene Ontology has been shown to offer significant benefits for the computational analysis of high-throughput data in the study of gene expression using hybridization microarrays [8], we anticipate similar benefits from the use of an ontology of cell types to support analysis of high-throughput, multidimensional flow data.

The relations has_high_amount and has_low_amount defined in terms of the geometric mean are used in the definition of cell types and are not meant to replace more complicated statistical methods for the analysis of flow cytometry data, such as is described in [40], or other cellular data. Such statistical methods can be applied to the analysis of individual flow data sets, while ontology definitions need to hold universally, across different experi- mental designs, protocols, and equipment and across differences in the resulting distributions of fluorescence intensities for reference cells. Indeed, the ontology definitions should hold across different assays for surface protein expression, and should not be tied directly to flow cytometry. We have therefore taken a relatively simple approach to the formulation of cell definitions that hold universally and that are supported by our current understanding of DC biology. It is our hope, however, that our work, taken together with [40], will encourage the use of more objective criteria in the analysis of flow cytometry data and in the description and analysis of cell types in general.

The classification of DCs is still an area of active research, thus DC-CL will continue to undergo revisions to keep current with new research results and new technologies for the characterization of cell types [28]. Because ontologies are based on an open world assumption, in contrast to relational databases, they are easily extended to include new subcategories. In addition, the formulation of DC-CL definitions as logically conjoined statements of the from $\mathrm{X} R \mathrm{Y}$ makes it easy to add or remove surface proteins from

Table 7: DC-CL disposition terms and their corresponding GO-BP terms.

\begin{tabular}{ll}
\hline DC-CL Disposition Term & GO BP Process Term \\
\hline $\begin{array}{l}\text { disposition to circulate in the blood } \\
\text { disposition to cross-present antigen to CD8+ T cells }\end{array}$ & $\begin{array}{l}\text { antigen presentation, exogenous antigen via MHC class I } \\
\text { disposition to migrate to the lymph node }\end{array}$ \\
$\begin{array}{l}\text { disposition to secrete anti-inflammatory cytokines } \\
\text { disposition to secrete inflammatory cytokines }\end{array}$ & \\
disposition to secrete type I interferon &
\end{tabular}


Table 8: Functions of each conventional DC subtype.

\begin{tabular}{|c|c|c|c|c|c|}
\hline & $\begin{array}{l}\text { antigen processing } \\
\text { activity }\end{array}$ & $\begin{array}{c}\text { cytokine secretion } \\
\text { activity }\end{array}$ & $\begin{array}{l}\text { macro- pinocytosis } \\
\text { activity }\end{array}$ & $\begin{array}{c}\mathrm{T} \text { cell antigen } \\
\text { presentation activity }\end{array}$ & $\begin{array}{c}\text { antigen transportation } \\
\text { activity }\end{array}$ \\
\hline CD8 $\alpha-C D \mid I b-D C$ & & + & & + & \\
\hline immature & + & + & + & + & + \\
\hline \multicolumn{6}{|l|}{$C D 8 \alpha-C D \mid I b-D C$} \\
\hline mature & & + & & + & \\
\hline \multicolumn{6}{|l|}{$C D 8 \alpha-C D \mid l b-D C$} \\
\hline$C D 8 \alpha-C D I I b+D C$ & & + & & + & \\
\hline immature & + & + & + & + & + \\
\hline \multicolumn{6}{|l|}{$\begin{array}{l}\text { CD8 } \alpha-C D \mid l b+ \\
\text { DC }\end{array}$} \\
\hline mature & & + & & + & \\
\hline \multicolumn{6}{|l|}{$\begin{array}{l}\text { CD8 } \alpha-C D \mid l b+ \\
\text { DC }\end{array}$} \\
\hline$C D 8 \alpha+C D \mid l b-D C$ & & + & & + & \\
\hline immature & + & + & + & + & + \\
\hline \multicolumn{6}{|l|}{$\begin{array}{l}\text { CD8 } 8+\text { CD I lb- } \\
\text { DC }\end{array}$} \\
\hline mature & & + & & + & \\
\hline \multicolumn{6}{|l|}{$\begin{array}{l}\text { CD } 8 \alpha+\text { CDI Ib- } \\
\text { DC }\end{array}$} \\
\hline interstitial DC & & + & & + & \\
\hline immature & + & + & + & + & + \\
\hline \multicolumn{6}{|l|}{ interstitial DC } \\
\hline mature & & + & & + & \\
\hline \multicolumn{6}{|l|}{ interstitial DC } \\
\hline Langerhans cell & & + & & + & \\
\hline $\begin{array}{l}\text { CDla+ Langerhans } \\
\text { cell }\end{array}$ & & + & & + & \\
\hline immature & + & + & + & + & + \\
\hline $\mathrm{CDIa}^{+}$ & & & & & \\
\hline \multicolumn{6}{|l|}{ Langerhans cell } \\
\hline mature $\mathrm{CDla}+$ & & + & & + & \\
\hline \multicolumn{6}{|l|}{ Langerhans cell } \\
\hline CD8 $\alpha^{\text {low }}$ & & + & & + & \\
\hline \multicolumn{6}{|l|}{ Langerhans cell } \\
\hline immature & + & + & + & + & + \\
\hline CD8 $\alpha^{\text {low }}$ & & & & & \\
\hline \multicolumn{6}{|l|}{ Langerhans cell } \\
\hline mature & & + & & + & \\
\hline CD8 $\alpha^{\text {low }}$ & & & & & \\
\hline \multicolumn{6}{|l|}{ Langerhans cell } \\
\hline dermal DC & & + & & + & \\
\hline $\begin{array}{l}\text { immature dermal } \\
\text { DC }\end{array}$ & + & + & + & + & + \\
\hline mature dermal DC & & + & & + & \\
\hline
\end{tabular}

+ indicates that the cell type referred to by the row label is related to the function indicated by the column heading using the has_function relation.

the definition of any cell type and to use a reasoner to assess consequences of the revision on the DC-CL hierarchy. Thus, newly discovered surface markers can be easily incorporated into the ontology. Furthermore, the system we have outlined is readily applicable to subcellular localizations other than the cell surface and to other cellular components such as mRNA molecules or cytoplasmic granules. In addition to defining more localization-specific relations like has_plasma_membrane_part, the general RO relations has_part and lacks can be used. For all of these relations, too, cellular components other than proteins and protein complexes can be used as arguments. 
Table 9: Functions of each plasmacytoid DC subtype.

\begin{tabular}{|c|c|c|c|c|c|}
\hline & $\begin{array}{l}\text { antigen processing } \\
\text { activity }\end{array}$ & $\begin{array}{c}\text { cytokine secretion } \\
\text { activity }\end{array}$ & $\begin{array}{l}\text { macro- pinocytosis } \\
\text { activity }\end{array}$ & $\begin{array}{c}\mathrm{T} \text { cell antigen } \\
\text { presentation activity }\end{array}$ & $\begin{array}{c}\text { antigen transportation } \\
\text { activity }\end{array}$ \\
\hline $\begin{array}{l}\text { immature CDIIC- } \\
\text { plasmacytoid DC }\end{array}$ & + & + & + & + & + \\
\hline $\begin{array}{l}\text { mature CDII I } \\
\text { plasmacytoid DC }\end{array}$ & & + & & + & \\
\hline immature CDI I clow & + & + & + & + & + \\
\hline $\begin{array}{l}\text { plasmacytoid DC } \\
\text { mature CDI I clow }\end{array}$ & & + & & + & \\
\hline
\end{tabular}

Other details as in Table 7.

Morphological characteristics such as size and shape can also be used to define cell types using the has_quality relation to link to the relevant qualities in PATO, the ontology of phenotypic qualities [41]. In this way, the DC-CL framework lends itself quite readily to the incorporation of new information as knowledge of DC biology increases.

We have built our representations of cell types in DC-CL by relating terms in the domains covered by the OBO Foundry ontologies using relations from the Foundry's relation ontology (RO) and creating new relations as needed. The OBO Foundry [6] was created in 2006 by a group of developers of OBO ontologies on the basis of an evolving set of principles designed to foster the pursuit of best practice in ontology development [13]. Its ontologies are designed to represent in an interoperable fashion the biomedical reality from which data are sampled. Their development within the framework of a common toplevel ontology (Basic Formal Ontology, BFO, [42]) and consistent employment of a common set of relations allows Foundry ontologies to be used together as modules of a larger system.

There are many benefits to building DC-CL from OBO Foundry ontologies. In addition to the formalism underlying Foundry ontologies ensuring their support for sophisticated computation both within and between ontologies, building from Foundry ontologies means extensive use of existing ontology resources, both eliminating redundant effort and providing a significant headstart to ontology development. By building on OBO Foundry ontologies, DC-CL is automatically interoperable with other ontologies that also build from Foundry ontologies and with the large information resources, such as UniProt, that use Foundry ontologies for their annotations, representing a wide base of existing annotations. Finally, as OBO Foundry ontologies, and in particular GO, are widely used, use of Foundry ontologies in constructing DC-CL improves the chances that DC-CL will be accepted by the biological ontology and database communities.

DC-CL will serve as a valuable information resource not only providing centralized access to existing information about DCs, but also providing standardized representations that allow algorithmic processing for data analysis and the testing of hypotheses. The consistent use of formally defined relations means that reasoners, such as those included in ontology editing software like OBOEdit and Protégé, can be reliably applied to DC-CL. In addition, representing information in DC-CL in the from of $\mathrm{XRY}$ statements, rather than in natural language definitions, means that DC-CL can be easily parsed, facilitating the implementation of custom algorithms for querying DC-CL or analyzing data annotated in its terms. For example, DC-CL can be queried for the list of proteins expressed by a certain cell type, for the list of cells that express a particular combination of proteins, or for the types of cells that participate in a particular process or have a particular function. We are currently working to integrate DC-CL into software designed for the analysis of flow cytometry data and to assess the ways in which the use of DC-CL can enhance flow data analysis.

\section{Conclusion}

DC-CL provides a prospectively highly valuable resource for the study of DCs. It further offers a generalizable method for the ontological representation of cells that offers significant benefits in the form of increasing the amount and accuracy of information contained in the ontology, enhancing support of the ontology for computation, and providing a much needed resource to support analysis of high-throughput, multidimensional flow data. Thus, we propose the method used to create DC-CL as a strategy for the representation of all cells of hematopoietic lineage.

\section{Abbreviations}

CL: Cell Ontology; DC-CL: Ontology of Dendritic Cell Types; DC: dendritic cells; RO: Relation Ontology; PRO: 
Table 10: Dispositions of the conventional DC subtypes.

\begin{tabular}{|c|c|c|c|c|c|}
\hline $\begin{array}{l}\text { disposition to } \\
\text { circulate in the } \\
\text { blood }\end{array}$ & $\begin{array}{c}\text { disposition to } \\
\text { cross-present } \\
\text { antigen to CD8+ T } \\
\text { cells }\end{array}$ & $\begin{array}{l}\text { disposition to } \\
\text { migrate to the } \\
\text { lymph node }\end{array}$ & $\begin{array}{l}\text { disposition to } \\
\text { secrete anti- } \\
\text { inflammatory } \\
\text { cytokines }\end{array}$ & $\begin{array}{l}\text { disposition to } \\
\text { secrete } \\
\text { inflammatory } \\
\text { cytokines }\end{array}$ & $\begin{array}{c}\text { disposition to } \\
\text { secrete type I } \\
\text { interferon }\end{array}$ \\
\hline
\end{tabular}

CD8 $\alpha-C D \mid l b-$

$\mathrm{DC}$

immature

CD8 $\alpha-C D$ I Ib-

$\mathrm{DC}$

mature

$+$

CD8 $\alpha-C D I I b-$

$\mathrm{DC}$

CD8 $\alpha-C D I I b+$
DC
immature
CD8 $\alpha-$
CDIIb+DC
mature
CD8 $\alpha-$
CDIIb+DC
CD8 $\alpha+$ CDIIb-
DC
immature
CD8 $\alpha+$
CDIIb-DC
mature
CD8 $\alpha+$
CDIIb-DC

interstitial DC
immature
interstitial DC
mature
interstitial DC

Langerhans cell

$\mathrm{CDla}+$

Langerhans cell

immature

$\mathrm{CDla}+$

Langerhans

cell

mature

$\mathrm{CDla}+$

Langerhans

cell

CD8 $\alpha^{\text {low }}$

Langerhans cell

immature

CD8 $\alpha^{\text {low }}$

Langerhans

cell

mature

CD8 $\alpha^{\text {low }}$

Langerhans

cell

dermal DC

immature

$+$

$+$

$+$

$+$

$+$

$+$

Page 17 of 19 
Table 10: Dispositions of the conventional DC subtypes. (Continued)

dermal DC
mature dermal
DC

+ indicates the cell type referred to by the row label is related to the disposition referred to by the column heading using the has_disposition relation.

Protein Ontology; GO CC: Gene Ontology Cellular Component Ontology; CD8 $\alpha^{+}$: possession of CD8 $\alpha$ molecules on the cell surface (similar notation is used for other molecules); CD8 $\alpha$ : absence of $\mathrm{CD} 8 \alpha$ molecules on the cell surface (similar notation is used for other molecules);

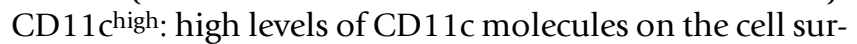
face (similar notation is used for other molecules); CD11clow: low levels of CD11c molecules on the cell surface (similar notation is used for other molecules); TLR: toll-like receptor; CARO: Common Anatomy Reference Ontology; IDO: Infectious Disease Ontology; BFO: Basic Formal Ontology; DC-KB: Dendritic Cell Knowledge Base.

\section{Authors' contributions}

AMM created both the Protégé and OBO-Edit versions of DC-CL, wrote all cell type definitions, participated in the formalization of the defined relations, and drafted the manuscript together with BS and LGC. CNA curated into the Protein Ontology all proteins referred to in DC-CL assertions and revised the manuscript. ADD and RHS contributed to the development of the conceptual framework for the revised Cell Ontology design and revised the manuscript. AEL participated in critical evaluation of the Cell Ontology, which formed the basis for developing the representation of cell types described in the manuscript. CJM participated in the formalization of the defined relations and revised the manuscript. BS participated in critical evaluation of the Cell Ontology, in developing the conceptual framework for the revised Cell Ontology design, in formalization of the defined relations, and in drafting the manuscript. LGC performed the critical evaluation of the Cell Ontology, conceived the described representation of cell types, formalized the defined relations together with BS, and drafted the manuscript together with BS and AMM. All authors read and approved the final manuscript.

\section{Acknowledgements}

LGC's contributions were supported by a Career Award from the Burroughs-Wellcome Fund, NIAID grant ROI AI077706, and NIAID grant ROI Al068804. AMM's contributions were supported by NIAID grant AI500I9. CNA's contributions were supported by NIH grant I ROI GM080646-0 I. ADD's contributions were supported by NHGRI grant HG002273. CJM's contributions were supported by NHGRI grant HG002273 and NIH grant HG004028-0I. RHS's contributions were supported by the NIAID through the Bioinformatics Integration Support Contract (NOI Al40076). BS's contributions were funded in part through the NIH Roadmap for Medical Research grant to the National Center for Biomedical Ontology (I U 54 HG004028). We would like to thank Luigi Racioppi and Bali Pulendran for helpful discussion of flow cytometry and dendritic cell biology. We would like to thank Melissa Haendel and Ceri Van Syke for helpful discussion of how to improve the Cell Ontology.

\section{References}

I. The Gene Ontology (GO) project in 2006. Nucleic Acids Res 2006:D322-326.

2. Blake JA, Eppig JT, Bult CJ, Kadin JA, Richardson JE: The Mouse Genome Database (MGD): updates and enhancements. Nucleic Acids Res 2006:D562-567.

3. Cherry JM, Ball C, Weng S, Juvik G, Schmidt R, Adler C, Dunn B, Dwight S, Riles L, Mortimer RK, et al.: Genetic and physical maps of Saccharomyces cerevisiae. Nature 1997, 387(6632 Suppl):67-73.

4. Grumbling G, Strelets V: FlyBase: anatomical data, images and queries. Nucleic Acids Res 2006:D484-488.

5. Camon E, Magrane M, Barrell D, Lee V, Dimmer E, Maslen J, Binns D, Harte N, Lopez R, Apweiler R: The Gene Ontology Annotation (GOA) Database: sharing knowledge in Uniprot with Gene Ontology. Nucleic Acids Res 2004:D262-266.

6. Open Biological Ontologies [http://www.obofoundry.org/]

7. National Center for Biomedical Ontology BioPortal [http:// bioontology.org/ncbo/faces/index.xhtml]

8. Lee JA, Sinkovits RS, Mock D, Rab EL, Cai J, Yang P, Saunders B, Hsueh RC, Choi S, Subramaniam S, et al.: Components of the antigen processing and presentation pathway revealed by gene expression microarray analysis following B cell antigen receptor (BCR) stimulation. BMC Bioinformatics 2006, 7:237.

9. Ruttenberg A, Clark T, Bug W, Samwald M, Bodenreider O, Chen H, Doherty D, Forsberg K, Gao Y, Kashyap V, et al.: Advancing translational research with the Semantic Web. BMC Bioinformatics 2007, 8(Suppl 3):S2.

10. Gupta A, Ludascher B, Grethe JS, Martone ME: Towards a formalization of disease-specific ontologies for neuroinformatics. Neural Netw 2003, 16(9): 1277-I 292.

II. Racunas SA, Shah NH, Albert I, Fedoroff NV: HyBrow: a prototype system for computer-aided hypothesis evaluation. Bioinformatics 2004, 20(SuppI I):i257-264.

12. Rubin DL, Shah NH, Noy NF: Biomedical ontologies: a functional perspective. Brief Bioinform 2008, 9(I):75-90.

13. Smith B, Ashburner M, Rosse C, Bard J, Bug W, Ceusters W, Goldberg LJ, Eilbeck K, Ireland A, Mungall C], et al.: The OBO Foundry: coordinated evolution of ontologies to support biomedical data integration. Nat Biotechnol 2007, 25(I I): I 25I-I 255.

14. Bard J, Rhee SY, Ashburner M: An ontology for cell types. Genome Biol 2005, 6(2):R2I.

15. Guarino N: Some ontological principles for designing upper level lexical resources. First International Conference on Language Resources and Evaluation. Granada, Spain 1998:527-534.

16. Steinman RM: Some interfaces of dendritic cell biology. APMIS 2003, II I (7-8):675-697.

17. Ueno H, Klechevsky E, Morita R, Aspord C, Cao T, Matsui T, Di Pucchio T, Connolly J, Fay JW, Pascual V, et al.: Dendritic cell subsets in health and disease. Immunol Rev 2007, 219:। I8- I42.

18. Pulendran B, Tang H, Denning TL: Division of labor, plasticity, and crosstalk between dendritic cell subsets. Curr Opin Immunol 2008, 20(I):6I-67.

19. Smith B, Ceusters W, Klagges B, Kohler J, Kumar A, Lomax J, Mungall C, Neuhaus F, Rector AL, Rosse C: Relations in biomedical ontologies. Genome Biol 2005, 6(5):R46.

20. Hill DP, Blake JA, Richardson JE, Ringwald M: Extension and integration of the gene ontology (GO): combining $G O$ vocabularies with external vocabularies. Genome Res 2002, I 2(12): 1982-199I.

21. Rosse C, Mejino JL Jr: A reference ontology for biomedical informatics: the Foundational Model of Anatomy. J Biomed Inform 2003, 36(6):478-500. 
22. Baader F, Nutt W: Basic Description Logics. In The description logic handbook: theory, implementation, and applications 2nd edition. Edited by: Baader F, Calvanese D, McGuinness D, Nardi D, Patel-Schneider P. Cambridge; New York: Cambridge University Press; 2007:43-95.

23. Sato K, Fujita S: Dendritic cells: nature and classification. Allergol lnt 2007, 56(3): |83-19|.

24. Natale DA, Arighi CN, Barker WC, Blake J, Chang TC, Hu Z, Liu H, Smith B, Wu CH: Framework for a protein ontology. BMC Bioinformatics 2007, 8(Suppl 9):SI.

25. The Gene Ontology project in 2008. Nucleic Acids Res 2008:D440-444.

26. Smith B, Kusnierczyk W, Schober D, Ceusters W: Towards a reference terminology for ontology research and development in the biomedical domain. Proceedings of KR-MED 2006 2006:57-65.

27. Stemberger C, Neuenhahn M, Buchholz VR, Busch DH: Origin of CD8+ effector and memory $\mathrm{T}$ cell subsets. Cell Mol Immunol 2007, 4(6):399-405.

28. McGrath KE, Bushnell TP, Palis J: Multispectral imaging of hematopoietic cells: where flow meets morphology. J Immunol Methods 2008, 336(2):91-97.

29. Snedecor GW, Cochran WG: Statistical methods. 8th edition. Ames: lowa State University Press; 1989:290.

30. Illario M, Giardino-Torchia ML, Sankar U, Ribar TJ, Galgani M, Vitiello L, Masci AM, Bertani FR, Ciaglia E, Astone D, et al:: Calmodulindependent kinase IV links Toll-like receptor 4 signaling with survival pathway of activated dendritic cells. Blood 2008 I I I(2):723-73|.

3I. Arighi C, Liu H, Natale D, Barker W, Drabkin H, Hu Z, Blake J, Smith $\mathrm{B}, \mathrm{Wu} \mathrm{C}$ : TGF-beta signaling proteins and the protein ontology. Bio-Ontologies 2008, Special Interest Group meeting, International Conference Intelligent Systems for Molecular Biology. Toronto, Canada 2008:25-29.

32. Roth MD: Interleukin 2 induces the expression of CD45RO and the memory phenotype by CD45RA+ peripheral blood lymphocytes. J Exp Med 1994, I79(3):857-864.

33. The Gene Ontology Tracker [https://sourceforge.net/tracker/ ?group id=36855\&atid=440764]

34. Smith B, Köhler J, Kumar A: On the application of formal principles to life science data: A case study in the Gene Ontology. In Data Integration in the Life Sciences (DILS) 2004 Springer; 2004:79-94.

35. Bouaud J, Bachimon B, Charlet J, Zweigenbaum P: Acquisition and structuring of an ontology within conceptual graphs. 2nd International Conference on Conceptual Structures: Workshop on Knowledge Acquisition using Conceptual Graph Theory 1994, 835: I-25.

36. Bodenreider $O$, Smith $B$, Kumar A, Burgun A: Investigating subsumption in SNOMED CT: an exploration into large description logic-based biomedical terminologies. Artif Intell Med 2007, 39(3): $183-195$.

37. Reis e Sousa C: Toll-like receptors and dendritic cells: for whom the bug tolls. Semin Immunol 2004, I 6(I):27-34.

38. Haendel M, Neuhaus F, Sutherland D, Mejino JLE JR, Mungall C, Smith B: CARO: the common anatomy reference ontology. In Anatomy Ontologies for Bioinformatics: Principles and Practice Edited by: Burger A, Davidson D, Baldock R. New York: Springer; 2008:327-349.

39. Infectious Disease Ontology [http://www.infectiousdiseaseon tology.org/]

40. Chan C, Feng F, Ottinger J, Foster D, West M, Kepler TB: Statistical mixture modeling for cell subtype identification in flow cytometry. Cytometry A 2008, 73(8):693-70I.

4I. PATO: the Ontology of Phenotypic Qualities [http:// www.obofoundry.org/cgi-bin/detail.cgi?id=quality]

42. Basic Formal Ontology [http://www.ifomis.org/bfo] Publish with Biomed Central and every
scientist can read your work free of charge

"BioMed Central will be the most significant development for disseminating the results of biomedical research in our lifetime. "

Sir Paul Nurse, Cancer Research UK

Your research papers will be:

- available free of charge to the entire biomedical community

- peer reviewed and published immediately upon acceptance

- cited in PubMed and archived on PubMed Central

- yours - you keep the copyright
BioMedcentral 